\title{
Lise Öğrencilerinin Yalnızlık Düzeyleri ile Akıllı Telefon Bağımlılığı Arasındaki İlişsii*
}

\section{The Correlation between High School Students' Loneliness Levels and Smart Phone Addiction}

\author{
Özlem ÇAKIR**, Ebru OĞUZ***
}

\begin{abstract}
Öz: Gençlerin teknoloji kullanımı ve buna bağlı olarak da akıllı telefon kullanımı gün geçtikçe artmaktadır. Gündelik yaşantıyı kolaylaştıran bu gelişme zaman zaman bazı sorunlara da neden olabilmektedir. Akıllı telefon kullanımı internet bağımlılı̆̆ı gibi tanımlanan bir bağımlılığa dönüşebilmektedir. Yalnızlık ise, dönemsel olarak ergenlikte daha fazla görülebilen bir durumdur. Bu nedenle de bu araştırmada lise öğrencilerinin yalnızlık düzeyleri ile akıllı telefon bağımlılığı arasındaki ilişki ortaya konulmaya çalışılmıştır. Araştırmanın çalışma grubunu, 2014-2015 öğretim y1lında Ankara'da bulunan kamu ve özel liselerden tesadüfi olarak seçilen toplam 540 lise öğrencisi oluşturmaktadır. Araştırmada iki farklı veri toplama aracı kullanılmıştır. Bunlar Demirci, Orhan, Demirdaş, Akpınar ve Sert (2014) tarafından Türkçeye uyarlanan Akıllı Telefon Bağımlılığı Ölçeği” ile Yıldız ve Duy (2014) tarafından uyarlaması yapılan "UCLA Yalnızlık Ölçeği-Kısa formu'dur. Araştırma bulgularına göre öğrencilerin akıllı telefon bağımlılığı ve yalnızlık düzeyleri orta düzeydedir. Akıllı telefon bağımlılı̆̆ ile yalnızlık arasında pozitif ve anlamlı ilişki bulunmaktadır.

Anahtar kelimeler: Yalnızlık, akıllı telefon bağımlılı̆̆ı, problemli telefon kullanımı, lise öğrencileri, ergenler
\end{abstract}

\begin{abstract}
Teenagers' usage of technology is getting increased day by day and so is the usage of smart phones. This development that makes daily lives easier can cause some problems at times. The usage of smart phone can be transformed into an addiction that can be described like internet addiction. Therefore, in this study it is aimed to reveal the correlation between high school students' loneliness levels and their smart phone addiction. The study group of the research is made up with 540 high school students, who were randomly selected from state and private high schools in Ankara in 2014-2015 education year. Two different data collecting tools were used in the study. One of them is "Smart Phone Addiction Scale", which was adapted into Turkish by Demirci, Orhan, Demirdaş, Akpınar and Sert (2014) and the other one is "UCLA Short Form of Loneliness Scale", which was adapted into Turkish by Yildiz and Duy (2014). According to research findings, the students' smart phone addiction and loneliness levels are in medium level. There is a significant and positive correlation between smart phone addiction and loneliness.

Keywords: Loneliness, smart phone addiction, problematic phone usage, high school students, adolescents
\end{abstract}

\section{Giriş}

Yalnızlık kavram olarak bakıldığında bireyin tek başınalığı anlamına gelmekteyken, günümüzde teknolojinin insanları yalnızlığa ittiği de bir gerçektir. Bundan 10-15 yıl öncesinde yalnızlık kavramı ile arkadaşı olmamak anlamını anlatırken, günümüzde bu kavram kişinin kendi dünyası içinde teknolojik aletlerle oynaması olarak ifade edilebilir.

Yalnızlık araştırmacılar tarafından bireyin yakın ve sosyal ilişkilerinde ki eksikliğinin bilişsel farkındalığ 1 , umutsuzluk, özlem duyma ve farkındalığa eşlik eden duygusal boşluk tepkileri olarak tanımlanan bir kavramdır (Asher ve Paquette, 2003; akt, Yıldız ve Duy, 2014).

\footnotetext{
* Bu çalışma Uluslararası Eğitim Kongresi: Gelecek İçin Eğitim Kongresinde sözlü olarak sunulmuştur.

**Doç. Dr., Ankara Üniversitesi, Eğitim Bilimleri Fakültesi, Bilgisayar ve Öğretim Teknolojileri Eğitimi, e-posta: ocakir@ankara.edu.tr

***Doç. Dr., Mimar Sinan Güzel Sanatlar Üniversitesi, Fen Edebiyat Fakültesi, Eğitim Bilimleri, e-posta:

oguz.ebru@gmail.com
} 
Peplau ve Perlman (1982) yalnızlığ insan ilişkileri bazında algılamakta ve kişinin gerçekte var olan ilişkilerinin bu konudaki beklentilerini karşılayamadığından kaynaklanan bir duygu olarak tanımlamaktadırlar. Yalnızlık, basit olarak, fiziksel bir yalnız olma durumundan doğan bir duygu değildir (Russell, Cutrona, McRae ve Gomez, 2012). Kişi diğerleri ile beraber olduğu zaman da yalnızlığı yaşayabilir (Rubenstein, Shaver ve Peplau, 1979, akt; Buluş, 1996).

Weiss'e (1973) göre, yalnızlık sosyal ve duygusal yalnızlık olmak üzere iki şekilde yaşanmaktadır (Duy, 2003). Sosyal yalnızlık, sosyal iletişim ağının eksikliğinden ya da ortak ilgi ve etkinliklerin paylaşıldığı bir grubun üyesi olamamaktan kaynaklanmaktadır. Bu sorun doyum verici bir sosyal ağa ulaşma ile çözümlenebilir. Ancak, duygusal yalnızlık, yakın bir bağl1lık ilişkisinin olmamasından ya da kaybedilmesinden kaynaklanmaktadır ve bu tür yalnızlıkta diğer insanlarla yakın ve içten ilişkiler kurulamamaktadır. Bireyin gelişme dönemlerinden biri olan ergenlik dönemi, bazı bireyler için rahat geçirilirken, bazı bireyler için büyük sorunlarla geçirilmektedir. Ergenlik yalnızlığın yoğun bir şekilde yaşandığı bir dönem olarak tanımlanmaktadır (Duy, 2003). Brennan (1982), ergenlik dönemindeki yalnızlığın bu derece yoğun ve yaygın yaşanmasının nedenlerini üç şekilde sınıflandırmıştır. Yalnız gencin karakteristik özellikleri olarak tanımlanan yatkınlıklar (utangaçlık, düşük öz saygı, zayıf sosyal beceriler) yalnızlığın nedenlerinden biridir. Diğer bir neden, gelişimsel değişimler ve bu değişimlerin gereksinimler ve ilişkiler üzerine etkisidir. Üçüncü neden ise, sosyal yapılar ve kültürel süreç, kısacası bireyin içinde bulunduğu yaştaki sosyal konumudur (akt: Özatça, 2001).

Yalnızlık, ergenler tarafından yaşanan "kimlik krizinin" sonucunda gerçeklesen bir durum olarak ifade edilmektedir. Ericson'ın (1963) gelişim dönemleri kuramına göre ergen, kimlik kazanmaya karşı rol karmaşası ve yakınlığa karşı yalıtılmışlık dönemi yaşamaktadır. Ericson, bireylerin kimlik kazanımından sonra diğer insanlarla yakın ilişkiler kurmaya ve bağl11ı yaşamaya hazır olduklarını belirtmiştir. Eğer başarılı bir kimlik kazanılmamış ise bu durumda bireyler yalıtılmışlık ve yalnızlık yaşamaktadırlar (akt: Yücel, 2009).

Son yıllarda mobil cihazlar hayatımıza büyük ölçüde yön vermeye başlamıştır. İlk zamanlarda sadece telefon görüşmesi ve kısa mesaj gönderimi gibi fonksiyonları içeren bu cihazlar günümüzde büyük bir değişim sürecine girmiştir. Bilgi ve iletişim teknolojileri arasında en yaygın olarak kullanılanları dizüstü bilgisayarlar, tablet bilgisayarlar ve akıllı cep telefonları olarak sayılabilir (Özbek, Alnıaçık, Koç, Akkılıç ve Kaş, 2014). Mobil cihazlar arasında akıllı telefonlar (smartphone) artık bir bilgisayardan farksız bir hale gelmiştir (Ada ve Tatl1, 2013). Türkiye İstatistik Kurumu verilerine göre 2010 yılında dünya çapında 305 milyon adet akıllı telefon satışının (Noyan, Enez-Darçın, Nurmedov, Yılmaz ve Dilbaz, 2015), 2013 yılında 1.04 milyar adet satışa ulaşmıştır (Özbek, Alnıaçık, Koç, Akkılıç ve Kaş, 2014). Akıllı telefonlara eklenen yeni özellikler, kolay taşınabilirlik gibi nedenlerden dolayı akıllı telefonların gittikçe yaygınlaşması çok doğaldır. Akıllı telefonlar ile telefon görüşmesi, kısa mesaj gibi normal telefonlarla yapılabilen işlemler yanında; görüntü ve ses kaydı, verilerin iletimi, internet erişimi, e-mail, anlık mesajların iletimi, dijital içeriğin görüntülenmesi, mobil uygulamalar, sosyal medya araçları, oyun gibi birçok uygulama kullanılabilmektedir.

Günümüzde mobil telefonlar bireylerin günlük yaşamlarının önemli bir parçası haline gelmiş ve diğer bireylerle bağlantı kurmak (Leena, Tomi ve Arja, 2005), aile üyeleri ve arkadaşları aramak, mesaj göndermek, mümkün olan her yer ve zamanda onlarla bağlantılı olmak, internete bağlanmak, oyun oynamak ve müzik dinleyip hoş vakit geçirmek (Coogan ve Kangas, 2001) için zorunlu bir araç olarak görülmeye başlanmıştır (Şar ve Işıklar, 2012). Ülkemizde 2011 yılındaki internet kullanım oranı \% 42,9 olup bunun \%4'ü akı1lı telefonlarla elde edilmekteyken, 2013 yılındaki internet kullanım oranı yaklaşı \%49 olup bunun \%16's1 telefonlardaki mobil bağlantılar yoluyla gerçekleşmektedir (TUIK, 2013). Akıllı telefon kullanımında gözlenen durum özellikle çocukların ve ergenlerin kullanımının yaygın olmasıdır. Türkiye İstatistik Kurumunun yaptırdığı bir araştırma (2010) Türkiye'de cep telefonu sahibi olma oranının \% 90 olduğunu göstermiştir; bu oran kentlerde \% 92,8 ve kırsal alanda \% 85 tir. $\mathrm{Bu}$ da cep telefonunun gençler arasında oldukça yaygın olduğunu göstermektedir (Şar, 2013).

Önceden internet bağımlılı̆̆ kavramı ön plandayken, şimdilerde bu kavramın yerini akı1lı telefon bağımlılığı kavramı almıştır (Kwon, Kim, Cho ve Yang, 2013). Bu yaygın 
kullanım, internet bağımlısı olan, oyun bağımlısı olan ve telefon bağımlısı olan kişilerin bağımlılıklarını pekiştirirken, bağımlı olmayanların da bağımlı olmalarına neden olabilmektedir (Demirci, Orhan, Demirdaş, Akpinar ve Sert, 2014).

Türkiye'de kullanımı giderek artan akıllı telefonların kontrolsüz ve aşırı kullanımına ilişkin çalışmalar, şu anki bilgimize göre bu durumu değerlendirmek üzere yapılan ölçek geçerlilik ve güvenilirlik çalışmalarıyla sınırlıdır. Akıllı telefon bağımlılığı tanımı, tanı ölçütleri, risk etkenlerinin ortaya konabilmesi, önleme ve tedavi girişimleri yapılabilmesi için akıllı telefonların kullanımı ve risk değerlendirme ile ilgili çalışmalara gerek vardır. Bu çalışmalarda kullanılabilecek, Türkçeye uyarlanmış ölçek sayısı sınırlıdır. Akıllı/mobil telefon bağımlılığını değerlendirmeye yarayan ölçekler genellikle Doğu Asya ülkelerinde geliştirilmektedir (Noyan, Enez-Darçın, Nurmedov, Yılmaz ve Dilbaz, 2015).

Akıllı telefon kullanımı hayatı kolaylaştırsa da, kullanım süresinin uzunluğu ve bununla birlikte günlük yaşamı olumsuz etkilemesi gibi sorunlara da neden olabilmektedir. Bu çalışmada lise öğrencilerinin akıllı telefon bağımlılığının yalnızlıklarına etkisi ortaya konulmaya çalışılacaktır. Araştırma kapsamında aşağıdaki sorulara yanıt aranmıştır:

1. Lise öğrencilerinin akıllı telefon bağımlılığı nasıldır?

2. Lise öğrencilerinin akıllı telefon bağımlılığı çeşitli faktörlere (cinsiyet, yaş, okul türü ve akıllı telefon kullanım süresi) göre farklılaşmakta mıdır?

3. Lise öğrencilerinin yalnızlık düzeyleri nasıldır?

4. Lise öğrencilerinin yalnızlık düzeyleri (cinsiyet, yaş, okul türü ve akıllı telefon kullanım süresi) göre farklılaşmakta mıdır?

5. Lise öğrencilerinin akıllı telefon bağımlığı ile yalnızlık düzeyleri arasındaki ilişski nedir?

\section{Yöntem}

Araştırma ilişkisel tarama modelinde bir çalışmadır. Araştırmada lise öğrencilerinin akıllı telefon bağımlılığı ve yalnızlığa ilişkin görüşlerinin nasıl olduğu ortaya konulmaya çalışılmıştır.

\section{Çalışma Grubu}

Çalışma grubuna ilişkin demografik bilgiler Tablo 1'de verilmiştir.

Tablo 1. Katılımcıların Cinsiyet, Yaş, Okul Türü Ve Akıllı Telefon Kullanım Süresine İlişkin Dă̆glımı

\begin{tabular}{lcc}
\hline Cinsiyet & $\mathrm{n}$ & $\%$ \\
\hline Kadın & 186 & 34,4 \\
Erkek & 354 & 65,6 \\
\hline Yaş & $\mathrm{n}$ & $\%$ \\
\hline 14 yaş & 19 & 3,5 \\
15 yaş & 111 & 20,6 \\
16 yaş & 183 & 33,9 \\
17 yaş & 153 & 28,3 \\
18 yaş & 73 & 13,5 \\
\hline Okul türü & $\mathrm{n}$ & $\%$ \\
\hline Kamu & 477 & 88,3 \\
Özel & 63 & 11,7 \\
\hline Kullanım Süresi & $\mathrm{n}$ & $\%$ \\
\hline 1 saat & 47 & 19,1 \\
saat & 32 & 13,0 \\
3 saat & 23 & 9,3 \\
4 saat & 250 & 46,3 \\
\hline
\end{tabular}


Çalışma grubunu, 2014-2015 öğretim yılında Ankara'da bulunan kamu ve özel liselerden tesadüfi olarak seçilen toplam 540 lise öğrencisi oluşturmaktadır. Araştırmaya katılan öğrencilerin 186'sı $(\%$ 34,4) kadın ve 354'ü $(\%$ 65,6) erkektir. Öğrencilerin yaş dağılımının ise; 14 yaş $(\% 3,5, \mathrm{n}=19), 15$ yaş $(\% 20,6, \mathrm{n}=111), 16$ yaş $(\% 33,9, \mathrm{n}=183), 17$ yaş $(\% 28,3, \mathrm{n}=153)$ ve 18 yaş $(\% 13,5, \mathrm{n}=73)$ olduğu görülmektedir. Öğrencilerin devam ettiği okul türleri ise, kamu $(\% 88,3, n=477)$ ve özel $(\% 11,7, n=63)$ olduğu görülmektedir. Öğrencilerin yarıya yakınının günde akıllı telefon kullanım süresinin 4 saat ve üzeri olduğu görülmektedir (\%46,3, n=250), bunu en az kullanım süresi olan 1 saat $(\% 19,1, n=47)$ takip etmektedir.

\section{Veri Toplama Araçları}

Araştırmada iki farklı veri toplama aracı kullanılmıştır. Bunlar "Akıllı Telefon Bağımlı1ı̆̆ Ölçeği” ile "UCLA Yalnızlık Ölçeği-Kısa formu'dur.

\section{Akıllı Telefon Bă̆ımlılık Ölçeği}

İlk Akıllı Telefon Bağımlılık Ölçeği Known tarafından Young'ın internet bağımlılığı ve akıllı telefonların geleceği ile ilgili maddelerine bağlı olarak geliştirilmiştir. Demirci, Orhan, Demirdaş, Akpınar ve Sert (2014) tarafından Türkçeye uyarlanmış bir ölçektir. Akıllı Telefon Bağımlılık Ölçeğinin Türkçe uyarlaması, akıllı telefon bağımlılığının değerlendirilmesinde geçerli ve güvenilir bir ölçme aracıdır. Akıllı Telefon Bağımlılık Ölçeğinin Türkçe uyarlamasının faktör analizi 7 faktörlü yapıdadır ve 0,349 dan 0,824 e kadar uzanan bir aralıkta olan maddelerin faktör yükleri ölçek için 0,947 olarak bulunmuştur. Akıllı Telefon Bağımlılık Ölçeği 6'lı Likert tipinde 33 maddeden oluşan kendini bildirim ölçeğidir. Bu ölçekteki seçenekler 1'den (kesinlikle değil) 6'ya (kesinlikle evet) kadar sıralanmıştır. Yüksek puanlar akıllı telefon bağımlılığı riskinin yüksekliğine işaret eder. Ölçekte ki toplam puan 33 ve 198 arasında değişebilmektedir.

\section{UCLA Yalnızlık Ölçeği (ULS-8)}

Ölçeğin kısa formunun uyarlanması Yıldız ve Duy (2014) tarafından yapılmıştır. Faktör analizi bir faktör olarak bulunmuştur. Maddelerin faktör yükleri 0,31 ve 0,71 arasında değişmektedir. Bütün uyum indeksleri ULS- 8 için iyi bir örneğe işaret etmiştir. Ölçüte dayalı geçerlik analizi yalnızlıkla genel aidiyet $(\mathrm{r}=0,71)$ ve yaşam doyumu $(\mathrm{r}=0,42)$ arasında önemli bir ilişki olduğunu ortaya koymuştur. Sonuçlar aynı zamanda faktörlerin iç tutarlık katsayılarının tüm ölçek için yüksek oranda yeterli olduğunu göstermiştir $(a=0,74)$. Test-tekrar test güvenirlik ölçekleri, iki haftalık bir sürede 64 lise öğrencili bir örneklemde $r=0,84, p<0.001$ olarak bulunmuştur.

\section{Verilerin Analizi}

Verilerin analizinde betimsel istatistik, ilişkisiz t-testi, Kruskal Wallis-H Testi, Mann Whitney U testi, ANOVA ve Pearson Korelasyon analizi kullanılmıştır. Lise öğrencilerinin akıllı telefon bağımlılığı ve yalnızlık düzeylerinin, cinsiyete ve okul türüne göre anlamlı farklılık gösterip göstermediğinin belirlenmesi amacıyla ilişkisiz t-testi yapılmıştır. Lise öğrencilerinin akıllı telefon bağımlılığı ve yalnızlık düzeylerinin, yaş düzeylerine göre anlamlı farklılık gösterip göstermediğinin belirlenmesi amacıyla ilişkisiz Kruskal Wallis-H Testi yapılmıştır. Farkın kaynağını tespit etmek için ise Mann Whitney U testi kullanılmıştır. Öğrencilerin akıllı telefon bağımlılığı ile yalnızlık düzeylerinin, internet kullanma sürelerine göre farklılaşıp farklılaşmadığının tespiti için ise ANOVA testi kullanılmıştır. Lise öğrencilerinin akıllı telefon bağımlılığı ve yalnızlık düzeyleri arasındaki ilişkiyi belirlemek amacıyla Pearson Korelasyon analizi yapılmıştır.

\section{Bulgular}

$\mathrm{Bu}$ bölümde öğrencilerin akıllı telefon bağımlılığı ve yalnızlık düzeylerine ilişkin görüşlerine yer verilmiştir. Tablo 2'de araştırmaya katılan öğrencilerin betimsel istatistikleri yer almaktadır. 
Tablo 2. Öğrencilerin akıllı telefon bă̆ımlılı̆̆ ve yalnızlık düzeylerine ilişkin betimsel istatistikler

\begin{tabular}{lccc}
\hline Akı1lı Telefon Bağımlılığı & $\mathrm{N}$ & $\mathrm{X}$ & $\mathrm{Ss}$ \\
\hline Rahatsız Edici Günlük Yaşam ve Tolerans & 510 & 18,56 & 7,54 \\
Geri Çekilme Belirtileri & 497 & 18,06 & 8,78 \\
Pozitif Beklenti & 511 & 16,59 & 6,14 \\
Siber-yönelimli ilişkiler & 525 & 8,92 & 6,14 \\
Aşırı Kullanma & 506 & 12,44 & 5,00 \\
Sosyal Ağ Bağımlılığı & 523 & 5,59 & 2,93 \\
Fiziksel Belirtiler & 520 & 7,89 & 3,082 \\
Akıllı Telefon Bağımlılığı & 540 & 90,03 & 29,71 \\
Yalnızlık & 529 & 12,65 & 4,74 \\
\hline
\end{tabular}

Öğrencilerin akıllı telefon bağımlılı̆̆ ölçeğinden aldıkları toplam puan ortalaması 90,03 olup, öğrencilerin orta düzeyde akıllı telefon bağımlısı olduğunu görülmektedir. Yalnızlık ölçeğinden aldıkları ortalama puan ise 12,65 olup, öğrencilerin orta düzeyde yalnız oldukları bulgulanmıştır.

Öğrencilerin akıllı telefon bağımlılığı ile yalnızlık düzeylerinin cinsiyet ve okul türüne göre farklılaşıp farklılaşmadığına ilişkin bilgiler Tablo 3'te yer almaktadır.

Tablo 3. Öğrencilerin akıllı telefon bă̆ımlılı̆̆ ve yalnızlı düzeylerinin cinsiyete göre farkı $t$ testi sonuçları

\begin{tabular}{|c|c|c|c|c|c|}
\hline & $\mathrm{N}$ & $\bar{X}$ & $\mathrm{~S}$ & $\mathrm{Sd}$ & $\mathrm{p}$ \\
\hline \multirow{4}{*}{ Rahatsız Edici Günlük Yaşam ve Toleran } & Kadın173 & 21,20 & 7,99 & \multirow{2}{*}{508} & \multirow{2}{*}{$5,83,000^{*}$} \\
\hline & Erkek337 & 17,20 & 6,92 & & \\
\hline & Kamu448 & 18,57 & 7,55 & \multirow{2}{*}{508} & \multirow{2}{*}{, 104, 918 } \\
\hline & Özel 62 & 18,47 & 7,53 & & \\
\hline \multirow{4}{*}{ Geri Çekilme Belirtileri } & Kadın170 & 19,65 & 8,92 & \multirow{2}{*}{495} & \multirow{2}{*}{$2,93,004^{*}$} \\
\hline & Erkek327 & 17,24 & 8,60 & & \\
\hline & Kamu438 & 18,52 & 8,91 & \multirow{2}{*}{495} & \multirow{2}{*}{$3,122,002 *$} \\
\hline & Özel 59 & 14,75 & 6,97 & & \\
\hline \multirow{4}{*}{ Pozitif Beklenti } & Kadın174 & 16,62 & 5,90 & \multirow{2}{*}{509} & \multirow{2}{*}{$0,88,930$} \\
\hline & Erkek337 & 16,57 & 6,26 & & \\
\hline & Kamu451 & 16,51 & 6,10 & \multirow{2}{*}{509} & \multirow{2}{*}{,837 } \\
\hline & Özel 60 & 17,22 & 6,44 & & \\
\hline \multirow{4}{*}{ Siber-Yönelimli İlişkiler } & Kadın182 & 8,844 & 4,80 & \multirow{2}{*}{523} & \multirow{2}{*}{,284, } \\
\hline & Erkek343 & 8,96 & 4,43 & & \\
\hline & Kamu465 & 9,24 & 4,59 & \multirow{2}{*}{532} & \multirow{2}{*}{$4,450,000^{*}$} \\
\hline & Özel 60 & 6,50 & 3,51 & & \\
\hline \multirow{4}{*}{ Aşırı Kullanım } & Kadın173 & 13,56 & 4,62 & \multirow{2}{*}{504} & \multirow{2}{*}{$4,808,000^{*}$} \\
\hline & Erkek333 & 11,35 & 5,03 & & \\
\hline & Kamu450 & 12,01 & 4,99 & \multirow{2}{*}{504} & \multirow{2}{*}{$1,294,196$} \\
\hline & Özel 56 & 12,92 & 5,06 & & \\
\hline \multirow{4}{*}{ Sosyal Ağ Bağımlılığı } & Kadın180 & 5,97 & 2,99 & \multirow{2}{*}{521} & \multirow{2}{*}{$2,150,032 *$} \\
\hline & Erkek343 & 5,39 & 2,88 & & \\
\hline & Kamu462 & 5,65 & 2,94 & \multirow{2}{*}{521} & \multirow{2}{*}{ 399, 318, } \\
\hline & Özel 61 & 5,25 & 2,87 & & \\
\hline \multirow{4}{*}{ Fiziksel Belirtiler } & Kadın180 & 8,51 & 3,12 & \multirow{2}{*}{518} & $3,353.001 *$ \\
\hline & Erkek340 & 7,56 & 3,01 & & $3,353,001$ \\
\hline & Kamu457 & 7,99 & 3,083 & & \\
\hline & Özel 63 & 7,17 & 3,002 & & \\
\hline
\end{tabular}




\begin{tabular}{|c|c|}
\hline \multirow{3}{*}{ Toplam Akıllı Telefon Bağımlılığı } & Kadın186 96,97 29,25 \\
\hline & Erkek354 86,39 29,33 \\
\hline & $\begin{array}{llll}\text { Kamu47790,698129,97 } & 538 & 1,424,155 \\
\text { Özel } & 63 & 85,03 & 27,38\end{array}$ \\
\hline \multirow{4}{*}{ Yalnızlık } & Kadın184 11,81 4,78 $5273010003 *$ \\
\hline & Erkek345 13,11 4,67 $5273,010,003^{*}$ \\
\hline & Kamu46613,0408 4,70 527 5,138,000* \\
\hline & Özel $63 \quad 9,84 \quad 4,15^{52 /} 5,130,000$ \\
\hline
\end{tabular}

Tablo 3'e göre araştırmaya katılan öğrencilerin akıllı telefon bağımlılı̆̆ cinsiyete göre anlamlı bir şekilde farklılaşmaktadır. Öğrencilerin ortalamaları karşılaştırıldığında, kadın öğrencilerin, erkek öğrencilere göre daha fazla akıllı telefon bağımlısı olduğu görülmektedir. Yalnızlık düzeyleri ise hem cinsiyet hem de okul türü değişkenlerine göre anlamlı bir şekilde farklılaşmaktadır. Erkek öğrencilerin, kadın öğrencilere göre yalnızlık düzeyleri daha yüksektir. Kamu okullarına devam eden lise öğrencilerinin, özel okullara devam eden lise öğrencilerine göre yalnızlık düzeylerinin daha fazla olduğu görülmektedir.

Öğrencilerin akıllı telefon bağımlılı̆̆ 1 ve yalnızlık düzeylerinin yaş değişkenine göre farklılaşıp farklılaşmadığına ilişkin bilgiler Tablo 4'te yer almaktadır.

Tablo 4. Öğrencilerin akıllı telefon bă̆ımlılı̆̆ ve yalnızlık düzeylerinin yaşa göre farkı Kruskal Wallis-H Testi sonuçları

\begin{tabular}{|c|c|c|c|c|c|c|c|}
\hline & Yaş aralığı & $1 \mathrm{n}$ & $\begin{array}{c}\text { Sira } \\
\text { Ortalamas1 }\end{array}$ & $\mathrm{Sd}$ & $\chi^{2}$ & $\mathrm{P}$ & Fark \\
\hline Rahatsız Edici & 14 yaş & 18 & 252,39 & \multirow{5}{*}{4} & \multirow{5}{*}{5,352} & \multirow{5}{*}{,253 } & \\
\hline Günlük Yaşam & 15 yaş & 107 & 239,75 & & & & \\
\hline \multirow[t]{3}{*}{ ve Tolerans } & 16 yaş & 169 & 255,75 & & & & \\
\hline & 17 yaş & 147 & 249,16 & & & & \\
\hline & 18 yaş & 68 & 290,45 & & & & \\
\hline Geri Çekilme & 14 yaş & 17 & 210,74 & \multirow{5}{*}{4} & \multirow{5}{*}{10,049} & \multirow{5}{*}{, 040} & $1-5(\mathrm{U}=340,50,026)$ \\
\hline \multirow[t]{4}{*}{ Belirtileri } & 15 yaş & 105 & 232,28 & & & & $2-5(U=2453,000,008)$ \\
\hline & 16 yaş & 167 & 237,13 & & & & $3-5(\mathrm{U}=4065,500,012)$ \\
\hline & 17 yaş & 145 & 259,32 & & & & \\
\hline & 18 yaș & 62 & 291,65 & & & & \\
\hline \multirow[t]{5}{*}{ Pozitif Beklenti } & 14 yaş & 17 & 261,94 & \multirow{5}{*}{4} & \multirow{5}{*}{5,520} & \multirow{5}{*}{,238 } & \\
\hline & 15 yaş & 108 & 238,21 & & & & \\
\hline & 16 yaş & 172 & 248,86 & & & & \\
\hline & 17 yaş & 145 & 259,78 & & & & \\
\hline & 18 yaş & 68 & 289,01 & & & & \\
\hline Siber-Yönelimli & 14 yaş & 18 & 235,44 & \multirow{5}{*}{4} & \multirow{5}{*}{11,976} & \multirow{5}{*}{018} & $2-3(U=7337,50,001)$ \\
\hline \multirow{4}{*}{ İlişkiler } & 15 yas & 107 & 295,71 & & & & $3-5(\mathrm{U}=5200,500,032)$ \\
\hline & 16 yaș & 177 & 237,76 & & & & \\
\hline & 17 yaș & 151 & 261,29 & & & & \\
\hline & 18 yaș & 71 & 283,55 & & & & \\
\hline \multirow{5}{*}{ Aşırı Kullanım } & 14 yaș & 18 & 234,11 & \multirow{5}{*}{4} & \multirow{5}{*}{11,718} & \multirow{5}{*}{,020 } & $2-3(U=7352,50,, 045)$ \\
\hline & 15 yas & 103 & 218,40 & & & & $2-4(\mathrm{U}=6332,50,027)$ \\
\hline & 16 yaş & 167 & 253,40 & & & & $2-5(\mathrm{U}=2607,00,002)$ \\
\hline & 17 yas & 147 & 260,12 & & & & $3-5(\mathrm{U}=4887,000,046)$ \\
\hline & 18 yaș & 70 & 292,87 & & & & \\
\hline & 14 yaș & 18 & 241,64 & \multirow{4}{*}{4} & \multirow{4}{*}{5,498} & \multirow{4}{*}{, 240} & \\
\hline \multirow{3}{*}{ Bağımlılı̆̆ 1} & 15 yaș & 108 & 239,03 & & & & \\
\hline & 16 yaș & 176 & 257,73 & & & & \\
\hline & 17 yaş & 150 & 277,96 & & & & \\
\hline
\end{tabular}




\begin{tabular}{|c|c|c|c|c|c|c|c|}
\hline & 18 yaş & 70 & 284,06 & & & & \\
\hline \multirow[t]{5}{*}{ Fiziksel Belirtiler } & 14 yaş & 19 & 272,05 & \multirow{5}{*}{4} & \multirow{5}{*}{7,439} & \multirow{5}{*}{, 114} & \\
\hline & 15 yaş & 109 & 244,29 & & & & \\
\hline & 16 yaş & 174 & 259,36 & & & & \\
\hline & 17 yaş & 147 & 251,05 & & & & \\
\hline & 18 yaş & 70 & 302,31 & & & & \\
\hline Toplam Ak1ll1 & 14 yaş & 19 & 250,71 & \multirow{5}{*}{4} & \multirow{5}{*}{11,740} & \multirow{5}{*}{,019 } & $1-5(\mathrm{U}=483,500,043)$ \\
\hline Telefon & 15 yaş & 111 & 251,76 & & & & $2-5(U=2987,500,003)$ \\
\hline \multirow[t]{3}{*}{ Bağımlılı̆̆ } & 16 yaş & 183 & 257,29 & & & & $3-5(U=4983,00,002)$ \\
\hline & 17 yaş & 153 & 275,45 & & & & $4-5(U=4671,500,047)$ \\
\hline & 18 yaş & 73 & 323,20 & & & & \\
\hline \multirow[t]{5}{*}{ Yalnızlık } & 14 yaş & 19 & 270,18 & \multirow{5}{*}{4} & \multirow{5}{*}{9,160} & \multirow{5}{*}{057} & \\
\hline & 15 yaş & 109 & 298,11 & & & & \\
\hline & 16 yaş & 179 & 244,62 & & & & \\
\hline & 17 yaş & 150 & 257,63 & & & & \\
\hline & 18 yaş & 71 & 276,03 & & & & \\
\hline
\end{tabular}

Tablo 4'te görüldüğü gibi, araştırmaya katılan öğrencilerin geri çekilme belirtileri yaş değişkenine göre farklılaşmaktadır $[\chi 2(4)=10,049, \mathrm{p}<.05]$. Farklılığın hangi gruplar arasında olduğunun belirlenmesi için Mann Whitney U-Testi yapılmıştır. Analiz sonucunda bu boyutta 14,15 ve 16 yaş ile 18 yaş arasında anlamlı bir farklılık olduğu görülmüştür.

Siber-yönelimli ilişkiler yaş değişkenine göre farklılaşmaktadır $[\chi 2(4)=11,976, p$ $<.05]$. Farklılığın hangi gruplar arasında olduğunun belirlenmesi için Mann Whitney U-Testi yapılmıştır. Analiz sonucunda bu boyutta 15 ile 16 yaş ve 16 ile 18 yaş arasında anlamlı bir farklılık olduğu görülmüştür.

Aşırı Kullanım yaş değişkenine göre farklılaşmaktadır [ $[\chi 2(4)=11,718, p<.05]$. Farklılığın hangi gruplar arasında olduğunun belirlenmesi için Mann Whitney U-Testi yapılmıştır. Analiz sonucunda bu boyutta 15 ile 16 yaş, 17 ve 18 yaş arasında ve 16 ile 18 yaş arasında anlamlı bir farkl1lık olduğu görülmüştür.

Toplamda akıllı telefon bağımlılı̆̆ yaş değişkenine göre farklılaşmaktadır [ $\chi_{2}(4)=$ $11,740, \mathrm{p}<.05]$. Farklılığın hangi gruplar arasında olduğunun belirlenmesi için Mann Whitney U-Testi yapılmıştır. Analiz sonucunda bu boyutta 14, 15, 16 ve 17 yaş ile 18 yaş arasında anlamlı bir farklılık olduğu görülmüştür.

Öğrencilerin akıllı telefon bağımlılı̆g 1 ve yalnızlık düzeylerinin kullanım süresi değişkenine göre farklılaşıp farklılaşmadığına ilişkin bilgiler Tablo 5'te yer almaktadır.

Tablo 5. Öğrencilerinakıllı telefon bağımlılı̆̆ ve yalnızlık düzeylerinin kullanım süresine göre farkı anova sonuçları

\begin{tabular}{|c|c|c|c|c|c|c|}
\hline & $\begin{array}{l}\text { Kareler } \\
\text { Toplamı }\end{array}$ & df & $\begin{array}{c}\text { Kareler } \\
\text { Ortalamas1 }\end{array}$ & $\mathrm{F}$ & Sig. & Fark \\
\hline \multirow{3}{*}{$\begin{array}{l}\text { Rahatsız Edici Günlük } \\
\text { Yaşam ve Tolerans }\end{array}$} & Gruplararas1 & 3620,280 & 3 & 1206,760 & \multirow{3}{*}{$24,115,000$} & $1-3$ \\
\hline & Gruplariçi & 25321,336 & 506 & 50,042 & & $1-4$ \\
\hline & Toplam & 28941,616 & 509 & & & $2-4$ \\
\hline \multirow[t]{3}{*}{ Geri Çekilme Belirtileri } & Gruplararas1 & 5200,72 & 3 & 1733,572 & \multirow{3}{*}{$25,837,000$} & $3-4$ \\
\hline & Gruplariçi & 33078,96 & 493 & 67,097 & & $1-3$ \\
\hline & Toplam & 38279,67 & 496 & & & $1-4$ \\
\hline \multirow[t]{3}{*}{ Pozitif Beklenti } & Gruplararas1 & 1400,58 & 3 & 466,861 & & $2-4$ \\
\hline & Gruplariçi & 17844,75 & 507 & 35,197 & \multirow[t]{2}{*}{$13,264,000$} & $\begin{array}{l}3-4,4- \\
2,4-3\end{array}$ \\
\hline & Toplam & 19245,34 & 510 & & & $1-3$ \\
\hline \multirow[t]{2}{*}{ Siber-Yönelimli İlişkiler } & Gruplararas1 & 298,91 & 3 & 99,638 & \multirow{2}{*}{$4,892,002$} & $1-4$ \\
\hline & Gruplariçi & 10612,04 & 521 & 20,369 & & $2-4$ \\
\hline
\end{tabular}




\begin{tabular}{|c|c|c|c|c|c|c|}
\hline & Toplam & 10910,95 & 524 & & & \\
\hline \multirow{3}{*}{ Aşırı Kullanım } & Gruplararas1 & 2205,31 & 3 & 735,102 & & $1-4$ \\
\hline & Gruplariçi & 10463,28 & 502 & 20,843 & $35,268,000$ & $2-4$ \\
\hline & Toplam & 12668,58 & 505 & & & \\
\hline \multirow{3}{*}{ Sosyal Ağ Bağımlılı̆̆ 1} & Gruplararas1 & 393,57 & 3 & 131,190 & & \\
\hline & Gruplariçi & 4096,10 & 519 & 7,892 & $16,623,000$ & $1-3$ \\
\hline & Toplam & 4489,68 & 522 & & & $1-4$ \\
\hline \multirow[t]{3}{*}{ Fiziksel Belirtiler } & Gruplararas1 & 148,86 & 3 & 49,618 & & $3-4$ \\
\hline & Gruplariçi & 4782,33 & 516 & 9,268 & $5,354,001$ & \\
\hline & Toplam & 4931,18 & 519 & & & $1-3$ \\
\hline \multirow[t]{3}{*}{ Yalnızlık } & Gruplararas1 & 311,54 & 3 & 103,848 & & $1-4$ \\
\hline & Gruplariçi & 11597,21 & 525 & 22,090 & 4,701,003 & $2-4$ \\
\hline & Toplam & 11908,75 & 528 & & & \\
\hline \multirow[t]{3}{*}{ Ak1llı Telefon Bağımlıl } & 1Gruplararası & 71867,60 & 3 & \multicolumn{2}{|l|}{23955,868} & \\
\hline & Gruplarici & 403933,66 & 536 & \multirow{2}{*}{753,608} & $31,788,000$ & $1-4$ \\
\hline & Toplam & 475801,26 & 539 & & & \\
\hline
\end{tabular}

Öğrencilerin akıllı telefon bağımlılı̆̆ı ile yalnızlık düzeyleri arasındaki ilişki arasındaki ilişkiye yönelik bulgular

Öğrencilerin akıllı telefon bağımlılı̆̆ 1 ile yalnızlık düzeyleri arasında bir ilişki olup olmadığına bakmak için Pearson Korelasyon analizi yapılmıştır. Analiz sonuçları Tablo 6'da yer almaktadır.

Tablo 6. Öğrencilerin pearson momentler çarpımı korelasyon katsayısı testi sonuçları $(N=540)$

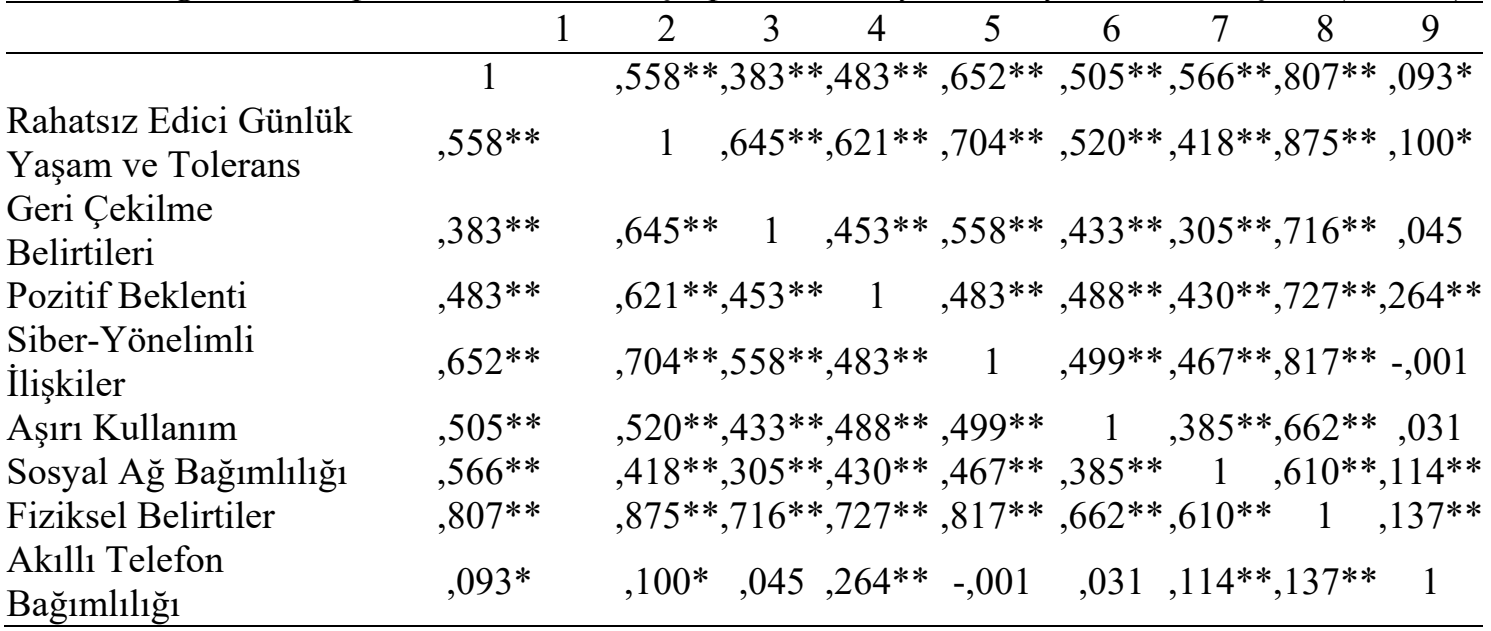

Tablo 6'ya göre öğrencilerin akıllı telefon bağımlılığı ve yalnızlık düzeyleri arasında pozitif ve anlamlı ilişki vardır. Boyutlara ayrıntılı biçimde bakıldığında; birinci boyutla (rahatsız edici günlük yaşam ve tolerans) yalnızlık arasında pozitif ve anlamlı ilişki olduğu görülmektedir $(\mathrm{r}=.093, \mathrm{p}<0,1)$. İkinci boyutla (geri çekilme belirtileri) yalnızlık arasında pozitif ve anlamlı ilişki olduğu görülmektedir $(\mathrm{r}=.100, \mathrm{p}<0,1)$. Dördüncü boyutla (siber-yönelimli ilişkiler) yalnızlık arasında pozitif ve anlamlı ilişki olduğu görülmektedir $(r=.264, p<0,1)$. Yedinci boyutla (Fiziksel Belirtiler) yalnızlık arasında pozitif ve anlamlı ilişki olduğu görülmektedir $(\mathrm{r}=.137, \mathrm{p}<0,1)$.

\section{Tartışma, Sonuç ve Öneriler}

Hızla artmakta olan teknoloji ile birlikte günümüz insanın teknolojiyi kullanım amacı ve kullandığı araçlar değişmektedir. Değişen bu teknoloji kullanımı ihtiyaçlarımıza cevap olurken, 
başka problemleri de gündeme getirmektedir. Bu araştırmada henüz ergen olarak nitelenen lise öğrencilerinin akıllı telefon bağımlılık durumlarının, yalnızlık düzeylerine etkisi incelenmiştir.

Araştırma sonuçlarına göre lise öğrencileri akıllı telefonu yoğun bir biçimde kullanmaktadır. Bu sonuç Şar'ın (2013) araştırma sonuçlarıyla da desteklenmektedir. Üniversite öğrencileriyle yapılan başka bir araştırmada öğrencilerin yarıdan fazlası telefonları yanlarında olmadığında kendilerini eksik hissettiklerini söylemişlerdir (Ay, 2008).

Araştırmaya katılan öğrencilerin yarıdan fazlası erkektir. Buna rağmen araştırmaya katılan kız öğrencilerin, akıllı telefon bağımlılıkları erkek öğrencilere göre daha yüksektir. Akıllı telefon bağımlılığında ve rahatsız edici günlük yaşam ve tolerans, geri çekilme belirtileri, aşırı kullanım, sosyal ağ bağımlılı̆̆ı, fiziksel belirtiler alt boyutlarında cinsiyet değişkenine göre anlamlı bir farklılaşma görülmektedir. Bu fark kız öğrenciler lehinedir. Kız öğrencilerin akı1lı telefonu daha çok kullandıkları, sosyalleşmelerini daha çok bu yolla sağladıkları buna karşın fiziksel belirtileri daha çok yaşadıkları söylenebilir. Bu sonucun aksine, Şar (2013)'e göre erkekler kızlara göre daha fazla problemli mobil telefon sorunu yaşamaktadır.

Araştırma bulgularına göre, erkek öğrencilerin yalnızlık düzeyleri, kız öğrencilere göre daha yüksektir. Bu bulgu Duyan, Çamur Duyan, Gökçearslan Çif̧ci, Sevin, Erbay, İkizoğlu, (2008) tarafından yapılan araştırma bulguları ile desteklenmektedir. Ayrıca üniversite öğrencileri için de durum değişmemektedir (Demirli, 2007; Sarıçam, 2011). Ancak bu sonucun tam aksine Şar (2013) kızların erkeklere göre daha çok yalnızlık yaşadıkları sonucuna ulaşmıştır.

Eskin'e (2001) göre yalnızlık duygusu lise öğrencisi ergenler arasında oldukça yaygın olarak görülmektedir, ancak cinsiyet değişkenine göre bir farklılaşma görülmemektedir. Ergenler, yalnızlıkla baş edebilmek için, edilgen etkinlik, ilişki arama, kendini etkinleştirme, okuma-ders çalışma ve düşünme-hayal etmeyi kullanmaktadır.

Okul türlerine göre akıllı telefon bağımlılığı ve yalnızlık düzeyleri arasında da anlamlı bir fark vardır. Siber-Yönelimli İlişkiler boyutunda kamu okuluna devam eden öğrencilerin ortalamalarının daha yüksek olduğu görülmektedir.

Yaş gruplarına bakıldığında akıllı telefon kullanımı toplamda ve alt boyutlarda farkl11ıklar göstermektedir. Akıllı telefonun en çok 18 yaş grubunda kullanıldığı görülmektedir. Yalnızlık düzeyleri ile yaş değişkeni arasında herhangi bir farklılık görülmezken, 15 yaşındaki öğrencilerin yalnızlığ 1 en çok yaşadığı söylenebilir. Ergenliğe geçiş dönemi olduğu düşünüldüğünde bu sonucun doğal olduğu söylenebilir.

Akıllı telefon kullanım süresi ile bağımlılık arasında da anlamlı bir fark vardır. Öğrencilerin yaklaşık yarısı günde dört saatten fazla telefon kullandığını belirtmiştir. Bu oranın da öğrencilerin okulda geçirdikleri saat düşünüldüğünde oldukça fazla olduğu görülmektedir. Öğrencilerin hangi amaçlarla akıllı telefon kullandıklarına bakıldığında, viber, tango, Skype, Whatsapp, Facebook, Foursquare, Twitter gibi Sosyal Medya Yazılımlarını ve CandyCrush vb. gibi oyun programlarını kullandıkları görülmektedir.

Öğrencilerin akıllı telefon bağımlılığı ve yalnızlık düzeyleri arasında pozitif ve anlamlı ilişki vardır ( $\mathrm{r}=.137, \mathrm{p}<0,1)$. Aynı şekilde Şar'e (2013) göre ergenlerde yalnızlık ve problemli telefon kullanımı arasında pozitif yönde, ancak telefon kullanma süresi ile yalnızlık arasında negatif yönde bir korelasyon bulunmaktadır. Buna göre yalnızlık arttıkça problemli telefon kullanımının da arttığı, ancak telefon kullanımı arttıkça yalnızlık duygusunun azaldığı, telefon kullanım süresi ile ilgili olarak bakıldığında kendini yalnız hisseden ergenlerin günlük daha fazla telefonla konuştukları ve problemli mobil telefon bağımlılığı problemi yaşamaktadırlar (Şar, 2013).

İlerideki çalışmalarda benzer araştırma farklı araştırma gruplarında denenebilir. Akıllı telefon bağımlılı̆̆ını yalnızlık ile birlikte başka nelerin etkilediği araştırılabilir.

\section{Kaynaklar}

Ada, S., Tatlı, H.S. (2013). Akıllı telefon kullanımını etkileyen faktörler üzerine bir araştırma. Online: http://ab.org.tr/ab13/bildiri/74.pdf, 10.04.2015 
Akın, A., Turan, M.E., Altundağ, Y., Akın, Ü., Uğur, E., Ercengiz, M. ve Yildiz, B. (2014, June). Ergenler için akıllı telefon bağımlılığı ölçeği'nin Türkçe formu'nun geçerlik ve güvenirliği. ERPA Congress, Haziran 6-8, İstanbul, Turkey.

Ay, S. (2008). İletişim araçları kullanımının yarattığı bağımlılığın sosyal izolasyon üzerindeki etkisi, cep telefonu kullanıcıları üzerinde bir çalışma. Bilgi Teknolojileri ve Illetişim Китити. İdari Uzmanlık Tezi.

Buluş, M. (1996). Ergen ögrrencilerde denetim odă̆g- yalnızlık düzeyi ilişkisi. Yayınlanmamış yüksek lisans tezi. İzmir: Dokuz Eylül Üniversitesi, Sosyal Bilimler Enstitüsü.

Demirci, K., Orhan, H., Demirdas, A., Akpinar, A., \& Sert, H. (2014). Validity and reliability of the Turkish version of the smartphone addiction scale in a younger population. Klinik Psikofarmakoloji Bülteni (Bulletin of ClinicalPsychopharmacology), 24(3), 226-34.

Demirli, A. (2007). Cinsiyetin, bağlanma tipinin ve aile yapısının üniversite ögrencilerinin yalnızlık düzeyi üzerindeki rolü. Yayımlanmamış yüksek lisans tezi. Ankara: Orta Doğu Teknik Üniversitesi.

Duy, B. (2003). Bilişsel-davranışçı yaklaşıma dayalı grupla psikolojik danışmanın yalnızlık ve fonksiyonel olmayan tutumlar üzerine etkisi. Yayınlanmamış doktora tezi. Ankara: Ankara Üniversitesi. Sosyal Bilimler Enstitüsü.

Duyan, V., Çamur Duyan, G., Gökçearslan Çifçi, E., Sevin, Erbay, Ç. ve İkizoğlu, M. (2008). Lisede okuyan öğrencilerin yalnızlık durumlarına etki eden değişkenlerin incelenmesi. Ĕ̈itim ve Bilim, 33(150).

Eskin, M. (2001). Ergenlikte yalnızlık, başetme yöntemleri ve yalnızlığın intihar davranışı ile ilişkisi. Klinik Psikiyatri. 4(5), 11.

Kwon, M., Lee J.Y., Won W.Y., Park, J.W., Min, J.A., Hahn, C., et al. (2013). Development and validation of a smart phone addiction scale (SAS). PLoSOne 2013; 8(2):e56936. doi: 10.1371/journal.pone.0056936.

Kwon, M., Kin, D.J., Cho, H., \& Yang, S. (2013). The smartphone addiction scale: Development and validation of a short version for adolescents. PLoS One 2013; 8 (12):e83558. doi:10.1371/journal.pone.0083558.

Noyan, C.O., Enez-Darçın, A., Nurmedov, S., Yılmaz, O. ve Dilbaz, N. (2015). Akıllı telefon bağımlılı̆̆1 ölçeğinin kısa formunun üniversite öğrencilerinde Türkçe geçerlilik ve güvenilirlik çalışması. Anadolu Psikiyatri Dergisi, 16, 73-81.

Özatça, A. (2001). Ergenlerde sosyal ve duygusal yalnızlı̆̆ı yordayıcısı olarak aile işlevleri. Yayımlanmamış yüksek lisans tezi. Adana: Çukurova Üniversitesi. Sosyal Bilimler Enstitüsü.

Özbek, V., Alnıaçık, Ü., Koç, F., Akkılıç, M.E. ve Kaş, E. (2014). Kişilik özelliklerinin teknoloji kabulü üzerindeki doğrudan ve dolaylı etkileri: Akıllı telefon teknolojileri üzerine bir araştırma. International Review of Economics and Management. 2(1). 36-57.

Peplau, L.A., \& Perlman, D. (1982). Loneliness: A sourcebook of currenttheory, research and therapy. New York: Wiley-Interscience.

Russell, D.W. Cutrona, C.E. McRae, C., \&Gomez, M. (2012). Is loneliness the same as being alone? The Journal of Psychology: Interdisciplinary and Applied, 146(1-2), 7-22.

Sarıçam, H. (2011). Üniversite öğrencilerinin reddedilme duyarlılıklarl ile benlik saygıları ve yalnızlı düzeyleri arasındaki ilişkinin incelenmesi. Yayımlanmamış yüksek lisans tezi, Erzurum: Atatürk Üniversitesi.

Şar, A.H. ve Işıklar, A. (2012). Problemli mobil telefon kullanım ölçeğinin Türkçeye uyarlamas1. International Journal of Human Sciences [Online], 9(2), 264-275.

Şar, A.H. (2013). Examination of lonelinessand mobil phoneaddiction problem observed in teenagersfromthesomevariables. The Journal of Academic Social Science Studies International Journal of Social Science, 6(2). 1207-1220.

Y1ldiz, M.A. ve Duy, B. (2014). Adaptation of the short-form of the UCLA loneliness scale (ULS-8) to Turkish for the adolescents. Düşünen Adam TheJournal of Psychiatry and Neurological Sciences, 27, 194-203. 
Yücel, N. (2009). Ergenlerin akran ilişkileri ve yalnızlık düzeylerinde evde internet kullanımının etkisinin incelenmesi. Yayımlanmamış yüksek lisans tezi. Ankara: Ankara Üniversitesi. Fen Bilimleri Enstitüsü.

\section{Extended Abstract \\ Introduction}

Loneliness means being alone as a concept; however, nowadays, it is a fact that technology cause people to get more isolated. Nearly 10 or 15 years ago, loneliness meant having no friends whereas this concept has changed its definition now and it means playing with technological devices in one's own world. Loneliness is described by researchers as a concept involving cognitive awareness of the individual on his/her deficiency in social and close relationships, and despair, longing or emotional emptiness reactions accompanying the awareness (Asher \& Paquette, 2003; cited in, Y1ldiz and Duy, 2014). Peplau and Perlman (1982) perceived loneliness in the context of human relations and described it as a feeling caused by their disappointment in their existing relationships. Loneliness is not a feeling simply resulting from being physically alone (Russell, Cutrona, McRae and Gomez, 2012). One can feel lonely when around others (Rubenstein, Shaver and Peplau, 1979, cited in: Buluş, 1996). The concept of internet addiction was the first issue before; nowadays the concept of smartphone addiction has replaced internet addiction (Kwon, Kim, Cho and Yang, 2013). This widespread usage reinforces people's internet, game or smartphone addictions. It can also cause people who do not have addictions to get addicted (Demirci, Orhan, Demirdaş, Akpinar and Sert, 2014).

\section{Method}

The study is in the relational screening model. The aim is to present high school students' smart phone addiction and their opinions about the loneliness.

\section{Result and Discussion}

According to the results of the study, high school students use smart phones largely. This finding is also backed up by Şar's (2013) study results. In another study conducted with university students, more than half of the students have said that they feel that something is missing when they do not have their smart phones with them (Ay, 2013).

More than half of the students who participated in the study were boys. However, smart phone addiction of the girls who participated in the study is higher compared to boys' addiction levels. It can be seen that there is a significant difference in smart phone addiction and in the sub-dimensions of Disturbing daily Life, Tolerance, Withdrawal, Overuse, Social Network, Physical Symptoms in terms of the gender variable. This difference is for the girls' favor. It can be said that girls use smart phone more and socialize through this way. On the other hand, they experience psychological symptoms more than the boys do. Contrary to this finding, according to Şar (2013), boys' usage of mobile phones is more problematic compared to girls.

According to research findings, the loneliness levels of male students are higher compared to female students. This finding is supported by the findings of the study conducted by Duyan, Gökçearslan, Çifçi, Sevin, Erbay and İkizoğlu (2008). Besides, this fact does not show any difference for university students (Demirli, 2007; Sarıçam, 2011). However, contrary to this finding, Şar found out that girls experience more loneliness than boys.

There is a significant difference between smartphone addiction and loneliness levels according to the types of school. It is seen that the mean scores of the students who attend state schools are higher in cyberspace dimension. There is a significant difference between smart phone addiction and usage time. Nearly half of the students stated that they use smart phones more than four hours a day. It is seen that this correlation is very high when the time they spend at school is considered. When their purpose of smart phone usage is examined, it is seen that they mostly use Social Media programs such as Viber, Tango, Skype, Whatsapp, Facebook, Twitter and games like Candy Crush. 
There is a positive and significant relationship between students' smart phone addiction and loneliness levels $(\mathrm{r}=.137, \mathrm{p}<0.1)$. Similarly, according to Şar (2013), in teenagers, there is a correlation between problematic smart phone usage and loneliness in a positive way but there is a negative correlation between smart phone usage time and loneliness. Accordingly, it was found that higher levels of loneliness increase problematic smart phone usage. However, overuse of smart phone decreases loneliness levels. When it is considered in terms of smart phone usage time, it is seen that teenagers who feel lonely speak more on the phone in a day and this results in mobile phone addiction. 